1

2

3

4

5

6

7

8

9

10

11

12

13

14

15

16

17

18

19

20

21

22

23

24

25

26

27

20 21 2 (3) 5 6

\title{
Curious bivalves: systematic utility and unusual properties of anomalodesmatan mitochondrial
} genomes

.

(1)

2

3

S. T. Williams ${ }^{a}{ }^{*}$, P. G. Foster ${ }^{a}$, C. Hughes ${ }^{a}$, E. M. Harper ${ }^{b}$, J. D. Taylor ${ }^{a}$, D. T. J. Littlewood ${ }^{a}$,

$$
\text { P. Dyal }{ }^{a}, \text { K. P. Hopkins }{ }^{a, c} \& \text { A. G. Briscoe }{ }^{a}
$$

${ }^{a}$ Natural History Museum, Cromwell Rd, London SW7 5BD, United Kingdom

${ }^{b}$ Department of Earth Sciences, University of Cambridge, Downing Street, Cambridge, CB2 3EQ,

United Kingdom

' Present address: Institute of Zoology, Zoological Society of London, Regent's Park, London, NW1 4RY, United Kingdom

27 *Corresponding author: S. T. Williams, email: s.williams@nhm.ac.uk 


\section{Highlights}

- The addition of seven anomalodesmatans improves relationships in bivalve mitogenomic tree

- Non-monophyly of Bivalvia may in part be the result of compositional heterogeneity

- Transcriptomic data helped determine boundaries for protein-coding genes

- We identified a possible case of gene duplication of ND5 in Myadora brevis

- We identified possible pseudogenes in published anomalodesmatan transcriptomic data

\section{Abstract}

Mitogenomic trees for Bivalvia have proved problematic in the past, but several highly divergent lineages were missing from these analyses and increased representation of these groups may yet improve resolution. Here, we add seven new sequences from the Anomalodesmata and one unidentified semelid species (Bryopa lata, Euciroa cf. queenslandica, Laternula elliptica, Laternula truncata, Lyonsia norwegica, Myadora brevis, Tropidomya abbreviata, "Abra"

sp.). We show that relationships in a mitogenomic tree for the Class are improved by the addition of seven anomalodesmatans from this highly divergent clade, but are still not completely consistent with relationships recovered in studies of nuclear genes. We suggest that some anomalous relationships (for instance the non-monophyly of Bivalvia) may be partially explained by compositional heterogeneity in the mitogenome and suggest that the addition of more taxa may help resolve both this effect and possible instances of long branch attraction. We also identify several curious features about anomalodesmatan mitogenomes. For example, many protein-coding gene boundaries are poorly defined in marine bivalves, but particularly so in anomalodesmatans, primarily due to non-conserved boundary sequences. The use of transcriptomic and genomic data together enabled better definition of gene boundaries, the identification of possible pseudogenes and suggests that most genes are translated monocistronically, which contrasts with many other studies. We also identified a possible case of gene duplication of ND5 in Myadora brevis (Myochamidae). Mitogenome size in the Anomalodesmata ranges from very small compact molecules, with the smallest for Laternula elliptica (Laternulidae) only 14,622 bp, to Bryopa lata (Clavagellidae) which is at least 31,969 bp long and may be $>40,000 \mathrm{bp}$. Finally, sampled species show a high degree of sequence divergence and variable gene order, although intraspecific variation in Laternula elliptica is very low.

Keywords: mitochondrial genome, gene boundaries, pseudogenes, bivalve, enrichment, systematics 


\section{Introduction}

The use of mitochondrial genomes (mitogenomes) in phylogenetics has had a varied history, depending on the organismal groups studied and the level of taxonomic resolution required. Offering complexity and phylogenetic signal across multiple levels (nucleotide, amino acid, gene order, RNA secondary structure), these ubiquitous, usually circular and high copy number molecules have been difficult to characterize with Sanger sequencing, but are rich in characters once secured. With limited intergenic spaces, usually with one large non-coding region and most often inherited asexually via the maternal line, a mitogenome can be considered as a single locus; typical mtDNAs encode 13 protein-coding, 2 ribosomal RNA and 22 tRNA genes. Unusual or conflicting phylogenetic resolution using mitogenomes, when compared to single or multiple nuclear gene phylogenies, combined with the cost of sequencing, has meant uneven taxon sampling across the Metazoa. However, denser and strategic taxonomic sampling of mitogenomes, recently facilitated by next generation sequencing methods for mitogenome characterization (Smith 2016), has led to improved substitution models and a better understanding of mtDNA evolution (Ballard \& Whitlock 2004). Together this has informed more robust phylogenetic analyses, which in turn has led to considering compelling evolutionary scenarios and testable hypotheses concerning interrelationships. Mitogenomes also offer some advantages over nuclear genes. For example, their high copy number makes them an ideal target for studies using ancient or degraded DNA samples (e.g. Dabney et al. 2013; Krause et al. 2010). Complete mitogenomes (or sequences from all transcribed genes) can also be obtained at no extra cost as the by product of NGS studies that may initially have another focus (e.g. Uribe et al. 2016a). As such, it is worth investigating the utility of the mt genome further as a phylogenetic marker.

Studies have shown that mitogenomes are capable of resolving robust phylogenies that are informative at both deep and shallow nodes in Mollusca. They have proved particularly useful for resolving cephalopod and gastropod relationships (e.g. Allcock et al. 2011; Uribe et al. 2016a; Williams et al. 2014). However, mitogenomes have proved less reliable in unravelling relationships within the Bivalvia. Recent phylogenetic analyses of bivalves using partial mitogenomes (Plazzi et al. 2011; Plazzi et al. 2010) resulted in well-supported phylogenies, but many nodes conflicted with previous phylogenies based both on nuclear genetic markers (e.g. Sharma et al. 2012; Taylor et al. 2007) and traditional morphologically-based concepts (Giribet \& Wheeler 2002). This incongruence suggested partial mitogenomes alone may not be useful for resolving bivalve relationships (Sharma et al. 2012). A later study using 12 protein-coding mitochondrial genes (effectively complete mitogenomes) from 18 bivalve taxa (Yuan et al. 2012) also shows some differences from nuclear gene trees. Expanded strategic taxon sampling has seen improvements of phylogenies within some 
molluscan subgroups (e.g. cephalopods, Allcock et al. 2011) and may yet help to resolve relationships within Bivalvia.

Taxon sampling across the bivalve clade has not been uniform in previous mitogenome studies, and anomalodesmatan bivalves have been poorly represented (Plazzi et al. 2011; Plazzi \& Passamonti 2010; Yuan et al. 2012). This is acknowledged by Plazzi and colleagues, who suggest that poor sampling of anomalodesmatans may be responsible for borderline measures of Average Taxonomic Distinctness and high variance in Taxonomic Distinctness of samples (Plazzi et al. 2011). At family level the anomalodesmatans account for approximately one sixth of extant bivalve diversity. This clade of early divergent 'heterodonts' has a long evolutionary history and today is represented by a wide variety of highly specialised and disparate species (Harper et al. 2006; Morton 1985). It includes some of the most specialised bivalves, including the tube-dwelling clavagelloids and an array of carnivorous taxa, known as the septibranchs, which have radiated into the deep sea where they account for half the diversity of Mollusca (Knudsen 1970). It is, at least in part, because of this degree of specialisation into unique and difficult to sample habitats that they have been underrepresented in phylogenetic analyses to date. Here we address the taxonomic imbalance through improved sampling.

Previously, one of the greatest obstacles to the use of mitochondrial genes in bivalve phylogenies has been that 'universal' mitochondrial primers do not work routinely across all taxa because the group is so divergent. We overcome this technical difficulty by using shotgun sequencing to obtain full mitogenomes for seven anomalodesmatans and one semelid species. One of these sequences was obtained using a new method for enrichment of mitochondrial DNA combined with shotgun sequencing which resulted in increased coverage. We use these data to determine whether the addition of anomalodesmatan bivalves helps resolve a bivalve phylogeny. We also discuss features of the mitochondrial genome focussing on those that are unusual or found predominantly in marine bivalves. 


\section{Materials \& methods}

\subsection{Sample collection and DNA extraction}

We sequenced the mitogenomes of seven anomalodesmatan species plus one semelid species, which had been originally identified erroneously as an anomalodesmatan. The taxa chosen provided good coverage of the diversity of Anomalodesmata ( 6 families) and included two carnivorous septibranch taxa (Tropidomya abbreviata and Euciroa cf. queenslandica; Table 1). Specimens were collected from a range of localities and depths and stored in $100 \%$ ethanol (see Table 1). A small $\left(5 \mathrm{~mm}^{3}\right)$ piece of tissue was removed from each sample for molecular analyses; the remainder of each specimen was accessioned in NHM (London) or MNHN (Paris) collections (Table 1). Total genomic DNA (gDNA) was extracted using the DNeasy Blood \& Tissue Kit (Qiagen) following manufacturer's recommendations. DNA was quantified using a Qubit fluorometer (Invitrogen). A mitogenome for one of our chosen species, Laternula elliptica, was published by another lab after this project had begun (NC_022846, Park \& Ahn 2015) (NC_022846, Park \& Ahn 2015)and was used for comparison.

\subsection{Mitochondrial DNA enrichment}

In order to increase the proportion of mitochondrial DNA within each genomic extract, which in turn increases the number of samples that can be multiplexed during sequencing, thus reducing costs, a hybridisation enrichment method was trialled. The entire mitochondrial sequence of Laternula elliptica was obtained by shotgun sequencing following the methods of Williams et al. (2014). Enrichment of two anomalodesmatan mitogenomes (L. rostrata and Bryopa lata) was attempted using the entire Laternula elliptica mitogenome in two overlapping fragments as bait.

Two primer pairs were designed using Primer3 with BLAST and global alignment algorithm to screen primers against the Mollusca database in order to avoid non-specific amplifications (Ye et al. 2012) (SW_PCR2_int_F4, CTTCTTCTTACTATTAACGCTC, SW_LongPCR_6R_COI, AATCATACTTAGGGAAGTGCCCATT; SW_LongPCR_3R_NAD2, ACCCCAAATCAATGGGTACTTGATA, SW_LongPCR_3F_COI, TGAATACCCTTTCACAGAAATTGGC). The first primer pair amplified a region $5,836 \mathrm{bp}$ long and the second primer pair amplified a region 9,316 bp long. The two fragments were produced by long range PCR using a TaKaRa LA PCR kit (Takara Bio Inc.) with $2.5 \mathrm{u}$ of Taq, $0.4 \mathrm{uM}$ of each primer, and cycling conditions: $94^{\circ} \mathrm{C}$ for 2 mins, followed by 30 cycles of $94^{\circ} \mathrm{C}$ for $20 \mathrm{~s}, 60^{\circ} \mathrm{C}$ for $30 \mathrm{~s}$, and $68^{\circ} \mathrm{C}$ for 9.5 mins, followed by 10 mins at $68^{\circ} \mathrm{C}$. 
The two PCR fragments were used as molecular probes for hybridisation capture following Maricic (2010) with minor but essential modifications. In order to account for an expected greater pairwise difference between the target and the probe sequence than has previously been shown to be successful, the annealing temperature during the hybridization step was reduced every 12 hours by $5^{\circ} \mathrm{C}$ (from $60-45^{\circ} \mathrm{C}$ over 48 hours). To elute the enriched library the supernatant was removed and discarded, without conducting any washes and the enriched library was eluted and cleaned following the standard protocol.

\subsection{Mitochondrial genome sequencing and assembly}

Indexed libraries were prepared for sequencing using a TruSeq Nano preparation kit (Illumina) incorporating the standard 8-cycle enrichment step. Due to degradation of gDNA, three specimens (Tropidomya abbreviata, Lyonsia norwegica, and Euciroa cf queenslandica) were subsequently amplified for 15 cycles in order to meet the concentration requirements of the library. All eight samples were sequenced on 1/5 of a flowcell on an Illumina MiSeq platform (v.2 chemistry; 2×250 paired-end). In addition, for specimens used in enrichment studies, unenriched indexed gDNA libraries were also sequenced in order to provide baseline coverage of the mitogenome from which success of the enrichment process could be judged (v.2 chemistry; $2 \times 300$ paired-end).

Following on-instrument de-multiplexing, raw sequencing reads were analysed and assembled using Geneious v.6.1.7. (https://www.geneious.com). The data were trimmed allowing no ambiguous base calls and removing bases from the terminal ends of reads with an error probability of 0.05 or higher (i.e. those with a greater than $5 \%$ chance of being incorrect). The trimmed reads were first assembled de novo and the resulting contigs were interrogated against the NCBI database, using BLAST (Altschul et al. 1990), in order to identify sequences of mitochondrial origin. Unassembled reads were then iteratively mapped and reassembled to the mitochondrial sequences until the resulting contig could be circularised. A published $28 \mathrm{~S}$ sequence from Abra alba (KF741656) was also used as a reference sequence to identify $28 \mathrm{~S}$ sequence from NGS raw reads for

\subsection{Mitochondrial genome annotation}

To verify the gene boundaries of our Laternula elliptica mitogenome, transcriptomic data was obtained from the NCBI Sequence Read Archive (SRA011054; (Clark et al. 2010) and assembled 
bivalves sequenced in this study, were putatively identified using MITOS (Bernt et al. 2013) and verified by visualization of open reading frames and comparison to alignments of molluscan mitochondrial genes including the corrected Laternula elliptica sequences.

Transfer RNA sequences (tRNAs) were identified using MITOS, DOGMA (Wyman et al. 2004) and ARWEN v. 1.2. (Laslett \& Canbäck 2008) and boundaries were determined by comparison of secondary structures. In cases where multiple locations were suggested for a tRNA, the options with the highest likelihood score were used except where these were considered invalid because of a large overlap with other existing tRNAs exhibiting a higher score. Secondary structures of tRNAs were drawn using mt-tRNA-Draw (Youngblood and Masta, unpublished).

\subsection{Phylogenetic analyses}

The eight new mitogenomes were included in phylogenetic analyses along with 98 bivalve mitogenomes downloaded from RefSeq representing all species sequenced (only one individual per species; June 2015) along with additional mitogenomes for Argopecten pupuratus (KF601246), Macoma balthica (KM373200) and Nucula nucleus (EF211991). A total of 87 gastropod sequences were downloaded from RefSeq along with Lunella aff cinerea KF700096). After preliminary analyses two bivalve genomes (NC_013659 Venustaconcha ellipsiformis and NC_015477 Utterbackia peninsularis, both freshwater palaeoheterodont taxa) were excluded as both were highly divergent from other genomes and both species are known to demonstrate doubly uniparental inheritance (Breton et al. 2011b). The sequence for the gastropod Lottia digitalis NC_007782 was also excluded because it was highly divergent, and its placement was not relevant to the aims of this study. A final total of published sequences for 87 gastropods and 99 bivalve taxa (+ eight new) was used in phylogenetic analyses.

Concatenated amino-acid sequences for all protein-coding genes were used in Bayesian analyses implemented in PhyloBayes (Lartillot et al. 2009). Preliminary analyses showed that protein sequences were highly diverged within Bivalvia, and use of DNA sequences in phylogenetic analyses was judged inappropriate given likely saturation. Complete genes were translated using NCBI translation table 5 for invertebrate mitochondria. Amino-acid sequences were aligned with Clustal Omega v 1.1.0 (Sievers et al. 2011). Gblocks v 0.91b (Casastrena 2000) was used to identify conserved sites in the alignment, using default settings except that parameter b5 was set to $h$ (alignment positions with half gaps allowed) (Table 2). Of the 99 bivalve mitogenomes from RefSeq, 51 had no ATP8 annotated, and one (NC_009081, pectinid Mizuhopecten yessoensis) had no COX2. Since so few species had ATP8 sequence, it was excluded from phylogenetic analyses. One bivalve 
species (NC_014590, Musculista senhousia) had two copies of COX2; only the first one, the longest, was used in analyses. ND4L was also excluded from analyses because most sites were removed by Gblocks (Table 2).

The results of phylogenetic analyses of two datasets are reported here. The first dataset included 87 gastropods and 107 bivalves (gastropods+bivalves). The final alignment was 1931 amino acids in length. In a second dataset we excluded all gastropods and two bivalves (Solemya velum NC017612 and Nucula nucleus EF211991) and re-ran phylogenetic analyses including the remaining bivalves (Autobranchia). The final alignment for the Autobranchia tree was 1918 amino acids in length and included 105 taxa. Phylogenetic analyses were undertaken using PhyloBayes (v. 4.1c Lartillot et al. 2009) with the CAT-Poisson model for the Autobranchia dataset and CAT+GTR for the gastropods+bivalves dataset, with the analysis run four times for the first dataset and five times for the second. A consensus tree was obtained from trees obtained from all runs. The gastropods+bivalves tree was drawn using the gastropods as outgroup to bivalves and the Pteriomorphia (36 species) were used as the outgroup to the remaining bivalves in the Autobranchia tree. The choice of outgroups was based on two recent phylogenomic studies (Kocot et al. 2011; Smith et al. 2011). tree (Foster 2004). Effects of heterogeneity were shown using a composition tree. For this, distance matrices were made based only on Euclidean distances between compositions of each sequence (equation 4 in Lockhart et al. 1994), then using BIONJ (Gascuel 1997) to tree those distances, and with support for nodes based on 200 bootstraps.

\subsection{Identification of semelid sp.}

The highest BLAST hits to the new $28 \mathrm{~S}$ and $\mathrm{COI}$ sequences for the small, unidentified semelid were to Macoma, Abra, Soletellina, Gari and Scrobicularia species (E value = 0; identity > 95\%). Although the semelid specimen was damaged and could not be identified to species morphologically, the presence of an internal ligament is consistent with placement in the genus Abra or Scrobicularia (or any semelid), but as Scrobicularia does not occur in the Indo-West Pacific we tentatively refer to it here as "Abra" sp. Another possible generic placement is Leptomya, but there are no published sequences for this genus. 


\section{Results}

250

251

252

253

254

255

256

257

258

259

260

261

262

263

264

265

266

\subsection{General features of the mitochondrial genome}

Complete mitogenomes were sequenced for seven of the eight bivalves studied (all new GenBank accession numbers in Table 3). Only the mitogenome for Bryopa lata was incomplete because it could not be circularised unambiguously, although every gene was found within the 31,969 bp sequence. Of the genomes studied the smallest genome was 14,622bp (in Laternula elliptica), with very short regions of non-coding sequence (longest non-coding region 78 bp; Table 3). Despite being incomplete, the $B$. lata genome was the largest of the seven species, at 31,969 bp with three large regions of non-coding sequence $(2,779,3,817,7,025 \mathrm{bp})$ (Table 3). High coverage of a repetitive region at the $3^{\prime}$ end of the linear fragment that was recovered (approximately eight times that seen across the rest of the genome), would suggest the complete $B$. lata mitogenome may be $>40,000$ bp in length. It is this highly repetitive region that prevented circularising and completing the mitogenome with confidence.

\subsection{Gene order and content}

Sequences corresponding to all 13 metazoan protein-coding genes, including ATP8, and two ribosomal (rRNA) genes were identified for all taxa. A possible instance of gene duplication was identified for ND5 in Myadora brevis.

All protein-coding, rRNA and tRNA genes were transcribed on the forward strand in the same orientation. Gene order, both of protein-coding genes and considering all genes, differed significantly among taxa in this study as indicated by whole genome alignments (Appendix A Supp. Data 2). However, gene order was identical for L. elliptica with a genome for the same species published on GenBank (NC_022846 Park \& Ahn 2015). Bryopa lata, L. elliptica and L. rostrata share the same gene order for protein-coding genes. Their gene order differs from Ly. norwegica only in the position of ND1 and ND2, which are moved to positions 12 and 13 respectively in rank order (Table 3).

\subsection{Gene boundaries}

All protein-coding gene boundaries for L. elliptica were confirmed by comparison with transcriptomic data, with the exception of the $3^{\prime}$ end of ATP8 and the $5^{\prime}$ end of COX3. The annotation of gene boundaries in our sequence and that in GenBank (NC_022846) differ by a several base pairs for both rRNA genes ( $\leq 3 \mathrm{bp}$ ), several tRNAs ( $\leq 7 \mathrm{bp}$ ) and three protein-coding genes ( $5^{\prime}$ ND4 $-21 \mathrm{bp}$, $5^{\prime}$ CYTB -6 bp and 5' COX3 $-9 \mathrm{bp}$ ). The extra $21 \mathrm{bp}$ at the $5^{\prime}$ end of ND4 in the published genomic 
sequence included a stop codon, but was translated in both our sequence and the transcriptomic sequence.

Alignments of protein coding genes showed that for many genes (e.g. COX1, ND3) there were no clearly conserved start or stop positions among the Anomalodesmata, or indeed among most marine bivalves. In such cases the beginning and end of each gene were determined by finding the closest possible initiation and termination codons to boundaries determined by reference to an alignment of all bivalves, excluding freshwater bivalves and pteriomorphs, as these taxa often started or stopped on a different residue. A truncated T stop codon was used if no other stop codon was present or to avoid an overlap of several amino acid residues with another protein-coding gene. Initial examination of transcriptomic data for L. elliptica suggested that there were two polycistronic transcripts, however, more careful examination of sequence data determined that there were small regions in reads occurring immediately before and after each gene that did not match when aligned to the complete genome. These sequences correspond to Illumina adaptors at the $5^{\prime}$ end and a poly-A tail at the $3^{\prime}$ end, suggesting that translation is monocistronic in this species with the exception of ATP8 and COX3, which appear to be translated together suggesting that there may be post-translational modification of these proteins. We also found an overlap of several base pairs between putative ATP8 and COX3 genes in Ly. norwegica, L. elliptica and L. rostrata; and between ATP8 and ND5 in Ly. norwegica. The fact that assembly of transcriptome reads produced apparently polycistronic products raises the possibility that reports of polycistronic translation may be exaggerated.

ND4 and ND4L overlapped by a few base pairs in Euciroa queenslandica and Ly. norwegica. More unusually in our initial annotation there was a single base overlap for ND3/ND4 in B. lata and for ND1/ND6 in L. rostrata. In both cases the overlap is the last base of a TAG stop codon. It is possible that these genes stop on T or TA, avoiding an overlap. Transcriptomic data suggest that all genes are transcribed separately (except ATP8 and COX3), which supports the idea of the shortened stop codon, however as no TA stop codons were identified for other genes or taxa in our study, we have conservatively retained the full stop codon in our annotation.

Protein-coding genes varied in length by 6-48 amino acid residues, with the greatest length variation seen in COX1 and COX2 (Table 3). More individual genes were longest in the semelid "Abra" sp.. Excluding this outgroup from the analysis reduced the length variation seen among proteincoding genes. 


\subsection{Initiation and termination of translation:}

The most common initiation codon was ATG (44\%; Tables 4 \& 5), the least common initiation codon was ATC (<1\%). An unusual start codon GTT was observed at relatively high frequency (9\%), but did not occur in the transcriptomic data. This start codon has also been recorded in nematodes (Okimoto \& Wolstenholme 1990), but not previously in bivalves to our knowledge. In every case where we have used the GTT start codon, the identification of the starting position was difficult to determine, so our choice must be considered tentative at this time.

Only three stop codons were identified: TAA (48\%), TAG (38\%) and a truncated stop codon where a single $T$ is completed by the addition of two $3^{\prime}$ A residues to the mRNA to produce a TAA stop codon (14\%) (Tables 4 and 5). All three codons were found in the transcriptomic data for $L$. elliptica.

\subsection{Pseudogenes}

In addition to confirming the gene boundaries within the mitogenome of Laternula elliptica, a number of reads were found in the published transcriptome that closely matched the $5^{\prime}$ end of the $\mathrm{COI}$ sequence but ended prematurely due to the presence of stop codons. This would suggest that pseudogenes were being translated and subsequently sequenced.

\section{6. tRNAs}

Sequences corresponding to 22 tRNAs were found for all species. Secondary structures could be determined for most putative tRNA genes, with the exception of some serine tRNAs (Appendix A Supp. Data 1). As in other bivalves some non-canonical conformations were observed including mismatches in base pairing in the aminoacyl acceptor arm and the anticodon stem.

\subsection{Intraspecific divergence}

With our new mitogenome sequence, three datasets were available for L. elliptica.

Comparison of published transcriptomic sequences with our shotgun sequence for L. elliptica identified only one base pair difference. On the other hand, our sequence differs from the GenBank genomic DNA sequence by 9 bp (one each in COX1, rRNA-L, tRNA-Asp, ND4, ND3, ND2, ND5, overlap between ATP8 and COX3, and COX3). 
Approximately four times enrichment was observed in the only congeneric tested, Laternula rostrata, with $0.38 \%$ of mitochondrial reads compared to $0.079 \%$ in an un-enriched library. There was no enrichment in test species from other genera.

\subsection{Phylogenetic analyses}

The runs did not converge in the Bayesian analysis of the gastropods+bivalves dataset. The topology of consensus trees of each of the five runs was not the same, but since all the differences were within the gastropod clade a consensus tree was calculated based on all trees (Fig. 1). The runs for the Autobranchia dataset converged on the same tree with a maxdiff among independent runs of 0.13 (Fig. 2).

In the gastropods+bivalves tree two protobranch bivalves (Solemya velum and Nucula nucleus) fall out in in the gastropod clade. One explanation for this finding may be that compositional effects are driving the apparent relationship between Protobranchia and the gastropods. A Pearson's chi-squared test on the gastropods+bivalves dataset using P4 (Foster 2004) was significant for compositional heterogeneity $(p=0.008)$. To determine whether this created any artefactual phylogenetic relationships we built a tree based only on Euclidean distances between compositions (Appendix A Supp. Data 3). In this sort of tree, closely related taxa are expected to have similar compositions, and so form clades. However, deeper nodes should have low support and relationships should not reflect systematic relationships if there is no compositional heterogeneity. Anomalous relationships that have good support may suggest phylogenetic effects due to their compositions. In our tree (Appendix A Supp. Data 3) clades were observed among major groups that were expected (e.g. Ostreidae, Pectinoida and Unionida). However we also observed that the two protobranch bivalves clustered with the gastropods, suggesting a weak compositional effect. 


\section{Discussion}

The explosive numbers of new mitogenomes appearing on public databases has been received with mixed reactions - are new mitogenomes more of the same or a useful addition? The relative ease with which mitogenomes can be fully characterised accurately, rapidly and costeffectively using NGS methodologies has allowed for more sampling of taxa for mitogenomic-based phylogenetics. However, it is sampling strategy in the context of available mitogenomes that determines utility and nodal resolution in phylogenetics. As an example, consider the evolution of mitogenomic studies in the context of wider phylogenomics in resolving annelid phylogenies; mitogenomic studies have contributed signal iteratively towards greater resolution until a threshold of taxonomic diversity partnered with strategic sampling reveals the endeavour to be worthwhile (Bleidorn et al. 2009; Weigert \& Bleidorn 2016; Weigert et al. 2016). Similar successes can be tracked for decapod crustaceans (Shen et al. 2013). In the current study, considering bivalve molluscs, a focus on using $11 \mathrm{mt}$ genes and additional anomalodesmatan taxa has provided an iterative step towards greater phylogenetic resolution (e.g. restoring Anomalodesmata to the Euheterodonta, unlike some earlier studies relying only on mt genes e.g. Plazzi et al. 2011; Plazzi \& Passamonti 2010) and suggests continued investment and focus still have more to offer.

\subsubsection{Systematic relationships within Bivalvia} supported in the mitogenome tree. While the Autobranchia are recovered as a clade, the protobranch bivalve genera Solemya and Nucula form a clade sister to non-Euthyneuran gastropods rather than with the rest of the bivalves (Fig. 1). Although some molecular analyses also failed to establish bivalve monophyly (Combosch et al. 2016; Giribet \& Distel 2003; Plazzi et al. 2013), recent analyses using multiple genes (Bieler et al. 2014), nuclear coding genes (Sharma et al. 2013) or transcriptomic RNA-seq (Gonzalez et al. 2015) with taxa from all molluscan classes as outgroups have recovered monophyly of the bivalves with the protobranch clade sister to all other bivalves. High support in the mitogenome tree for the unexpectedly close relationship between protobranch bivalves and gastropods may be explained in part by compositional heterogeneity biasing the analyses (e.g. Rota-Stabelli et al. 2013). Alternatively, this relationship may reflect some genuine shared relationship between protobranchs and gastropods. Both protobranch genera sampled have an extended fossil record originating in the early Ordovician and have some morphological features not present in other bivalves but similar to basal gastropod features, including the large 
hypobranchial gland of Solemya species (Taylor et al. 2008) and the leaflet ctenidia not used for filter feeding; in Solemya leaflet ctenidia have been modified to house chemosymbiotic bacteria.

In the Autobranchia tree we recover Pteriomorphia and Heteroconchia with moderate support ( $\mathrm{PP}=0.89$; Fig. 2), although Heteroconchia is not recovered in the bivalves+gastropods tree, as Pteriomorphia is sister to Euheterodonta (Fig. 1). Paleoheterodonta and Euheterodonta are both recovered in all analyses, although with high support only in the gastropods+bivalves tree (PP $\geq 0.98$; Fig. 1). Superfamilies are well supported within the Autobranchia bivalve tree (Fig. 2) but the relationships among superfamilies are less clear. Trees from prior molecular analyses also show varying topologies for the relative positions of the different major clades (e.g. Bieler et al. 2014; Combosch \& Giribet 2016; Giribet \& Distel 2003; Giribet \& Wheeler 2002; Sharma et al. 2012; Steiner \& Hammer 2000).

A recent transcriptomics study of the Pteriomorpha establishes monophyly of the group and recovers Mytilida as sister to Ostreida, with Arcida as sister to all other pteriomorph taxa (Lemer et al. 2016). Our tree agrees with this study in that it finds a well-supported pteriomorph clade and clades for super families were also recovered. However, relationships among superfamilies differ markedly. Mytilida is sister to all pteriomorphs with Arcida then sister to Pectinoidea+Pterioidea. Pinnoidea, represented in this study by Atrina pectinata, clusters in a well-supported clade with Pterioidea and Ostreoidea. This topology is supported by some previous analyses (e.g. Giribet \& Distel, 2003; 5 gene analysis of Bieler et al. 2014) but not others (e.g. Sharma et al 2012; nine gene analysis of Bieler et al. 2014) where Pinna carnea groups with Mytilidae. New genomic analysis (Lemer et al. 2016) places Pinnoidea as sister to Pterioidea+Ostreoidea. Shell microstructure would suggest a closer relationship of Pinnoidea with Pterioidea than with Mytiloidea (compare Checa et al. 2014; Checa et al. 2005).

The Heterodonta are highly divergent with the Palaeoheterodonta distantly separated from the Euheterodonta. Although there are a number of mitogenomes published for Palaeoheterodonta species (Unionoidea + Trigonoidea) it is disappointing that there are none published for any species from the Archiheterodonta (Crassatellidae, Carditidae, Astartidae, Condylocardiidae). This is unfortunate because in recent molecular analyses the palaeoheterodonts and archiheterodonts form early divergent branches of the heteroconch bivalves but their relative positions appear unresolved; in the nine gene analysis of Bieler et al. (2014) Archiheterodonta form the basal branch but transcriptome data (Gonzalez et al. 2015) indicates that the Palaeoheterodonta form the basal split. Surprisingly, the mitochondrial gene trees of Plazzi et al. (2011) show Cardita and Astarte grouping within the Pteriomorpha, a finding not supported by other studies. 
Within the Euheterodonta, the Anomalodesmata form a sister clade to all the other euheterodonts confirming a topology recovered in molecular analyses based on nuclear genes (e.g. Bieler et al. 2014; Gonzalez et al. 2015; Sharma et al. 2012; Taylor et al. 2007), but differing from earlier studies based only on four mitochondrial genes (Plazzi et al. 2011; Plazzi \& Passamonti 2010). Within the Imparidentia (non-anomalodesmatan euheterodonts) major superfamilies are well differentiated and well supported but data for many families are lacking. The grouping of the two superfamilies Solenoidea and Hiatelloidea (Adapedonta) has been recognised in previous molecular analyses (Bieler et al. 2014; Giribet \& Wheeler 2002; Taylor et al. 2007). This contradicted previous assertions based on morphology that the Hiatelloidea were members of the Myoida. To date there are no strong morphological apomorphies that unite the two clades. In the present mitogenome tree, Hiatella is separate on a long branch from the two Panopea species although in other published gene trees it groups with Panopea (Bieler et al. 2014; Taylor et al. 2007) as a monophyletic Hiatelloidea.

The Tellinoidea and Cardioidea grouping in the Autobranchia tree (Fig. 2), although not well supported, has been recovered in other molecular phylogenies (Bieler et al. 2014; Taylor et al. 2007). As yet there are no obvious shared morphological apomorphic characters.

The remainder of the Imparidentia heterodonts - superfamilies Myoidea, Mactroidea, Arcticoidea and Veneroidea form a well supported clade and this grouping with other included families, named Neoheterodontei by Taylor et al. (2007), has been recovered in other molecular analyses (Bieler et al. 2014; Combosch et al. 2016; Giribet \& Distel 2003; Giribet \& Wheeler 2002).

\subsubsection{Systematics of Anomalodesmata}

The coral boring clavagelloidean Bryopa lata is included in analyses for the first time and groups in a well-supported subclade with Lyonsia norwegica. Previous 18S RNA analyses also showed a relationship between the clavagelloideans (Clavagella, Brechites and Penicillus) and pandoroidean, Lyonsia norwegica (Harper et al., 2006). Although it is tempting to consider the carnivorous septibranchs as a single clade, the two morphologically and taxonomically distinct septibranch taxa

461 (Tropidomya and Euciroa) do not cluster together in our analysis, as has proved the case in previous studies with different taxa (Bieler et al. 2014; Harper et al. 2006). 


\subsubsection{Systematic relationships within Gastropoda}

Although not the focus of this study, a large number of gastropods were included in phylogenetic analyses (Fig. 1). As discussed above, Gastropoda is made non-monophyletic by the inclusion of protobranch bivalves as sister to Vetigastropoda and Caenogastropoda. The major clades Vetigastropoda, Caenogastropoda and Euthyneura are all recovered with strong support ( $P P=1)$. Vetigastropoda is sister to Caenogastropoda with high support $(P P=1)$. Sampling within this clade is limited, but the sister relationship between Fissurellidae and Haliotidae is not supported by recent mitogenomic studies focussing on this group (Lee et al. 2016; Uribe et al. 2016a; Uribe et al. 2016b; Wort et al. 2016). Of the three caenogastropod orders, only Architaenioglossa is monophyletic; the monophyly of this group is consistent with morphological studies (Strong 2003). As in other molecular studies, Littorinimorpha and Neogastropoda are non-monophyletic (e.g. Cunha et al. 2009; Osca et al. 2015; Williams et al. 2014). The Euthyneura clade unexpectedly is more like previous molecular phylogenies including nuclear genes than previous mitogenomic studies, in that it has opisthobranchs as a grade diverging early in the tree and a clade of Panpulmonata (see Wägele et al. 2013, for a review).

\subsection{Properties of anomalodesmatan mitochondrial genomes}

A number of interesting or curious features were discovered in the mitogenomes for the specimens sequenced in this study. In particular we identified problems with determining gene boundaries, a possible incidence of gene duplication, a large range of genome sizes, evidence of pseudogenes in transcriptomic data, and evidence of low levels of intra-specific divergences but very high interspecific divergences. Some of these characteristics are common to all marine bivalves, but others are quite unusual.

\subsubsection{Protein-coding genes}

Determining gene boundaries for protein-coding genes (PCG) in the Anomalodesmata was not straightforward, exemplifying problems noted for other marine bivalves (e.g. Wang et al. 2010). Using GenBank sequences to infer protein-coding boundaries is problematic as this relies on a circular argument of support. Many gene boundaries have been determined using the same software programmes and few, if any, molluscan proteins have been confirmed experimentally. In this study we used transcriptomic data to help determine gene boundaries for protein-coding genes in Laternula elliptica, which helped inform our choice of boundaries in other species. This goes some 
way towards improving the confidence with which we can state that marine bivalves do not seem to have the same conservation of initiation and termination boundaries seen in other groups. Surprisingly, we noticed that freshwater bivalves, gastropods and cephalopods show greater conservation of $5^{\prime}$ gene boundaries than marine bivalves, especially in COX1.

Mitochondrial PCG are notorious for the use of non-standard initiation and truncated stop codons (Boore 2006; Carapelli et al. 2008). We found seven start codons, including one non-typical start codon (GTT), which occurred in six taxa and six genes (three times for ND3). This codon has also been found to initiate translation in nematodes (Okimoto \& Wolstenholme 1990), but may also reflect difficulties in defining where some genes were initiated.

The ATP8 gene is often thought to be absent from marine bivalve mitogenomes (e.g. Boore et al. 2004; Mizi et al. 2005) and is also thought to be missing or truncated in Nematoda, Placozoa, Platyhelminthes, Annelida, and Sipunculida (Kim et al. 2013). Curiously, it is not missing from freshwater bivalves or gastropods. It has been suggested that the bivalve gene may have been transferred to the nucleus or may be difficult to identify and therefore overlooked during gene annotation (Wang et al. 2010; Wu et al. 2012a; Wu et al. 2012b). In this study we identified regions corresponding to a putative ATP8 gene for all eight taxa examined. There is a conserved start for freshwater bivalves (MPQLSPMSW) but for these anomalodesmatans only the first few residues (MPQ or MPH) are conserved although some later residues are also conserved. The MPH start is shared with lucinid genera Loripes and Lucinella and the pectinid Mimachlamys. MAQ is another conserved start found in venerids (Fulvia, Paphia and Meretrix) and Panopea (Hiatelloidea). Although all eight of our species, seven anomalodesmatans and one semelid, had an ATP8 gene, in some cases the gene is short or overlaps another protein-coding gene by several residues. ATP8 genes of similar lengths to the shorter anomalodesmatan genes are found in some other marine bivalves (e.g. lucinids and several Paphia, Meretrix and Panopea species). It is not clear whether such genes are functional; it may be possible to map gene loss over the bivalve tree and show that gene loss is phylogenetically constrained.

A possible case of gene duplication was observed in the mitogenome of the myochamid anomalodesmatan Myadora brevis. An open reading frame (ORF) of 1,623 bp with an ATG start and a TAA stop codon was identified between ND5 and ATP8. A BLASTX search against Mollusca showed that approximately 700 bp brings up matches to molluscan ND5 sequences and a putative conserved region matching the oxidored_q1 superfamily. The ORF is AT rich (AT: 67.6\%), showing a similar composition to the (putatively) functioning ND5 gene (AT: 69\%), but they share no significant similarity at the nucleotide level in a BLASTn comparison. We do not have any EST or transcriptomic data to determine if this region is being expressed, but novel genes have been identified in other 
530 bivalve mitogenomes, leaving open the possibility that this ORF may serve a biological function.

531 Curiously, an ORF of 963 bp was identified in the pteriomorph Pinctada maxima mitogenome (Wu et 532 al. 2012b), with an ATG start codon, TAA stop codon and the same putative conserved domain as detected in our sequence. These authors found that the gene was highly expressed in EST data from GenBank and suggest that it may play an important role in biological functions (Wu et al. 2012b). Other genes found in the mitogenome in other studies include a protein-coding gene that is likely involved in bivalve species with doubly uniparental inheritance (DUI) (Breton et al. 2011a; Breton et al. 2011b) and a C-terminus extended, male-transmitted COX2 protein in a freshwater bivalve that is thought to play a role in reproduction (Chakrabati et al. 2007). The marine bivalve Venerupis, which also exhibits DUI, also has a second tandem copy of COX2 (Serb \& Lydeard 2003). Rapid divergence following a duplication of ND2 may have given rise to two novel genes in two species of Crassostrea oysters (Wu et al. 2012a). Examples from other taxa are given in Breton et al. (2014)

\subsubsection{Genome size}

The mitogenomes in this study range from very small compact molecules, with the smallest for L. elliptica only 14,622 bp to very large genomes. The largest genome is found in B. lata, which is at least 31,969 bp long. This genome is incomplete, or at least cannot be readily circularized, because of an extensive repeat region in a non-coding area; a convincing overlap could not be found in the assembled sequence. It is likely that this genome is in fact significantly larger than 32,000 bp as coverage for the genome was not even, with the non-coding portion receiving eight times higher coverage than coding portions of the genome, suggesting a total size $>40,000 \mathrm{bp}$.

The range of genomes sizes found in anomalodesmata fit within the range observed for other molluscs. The smallest molluscan mitogenome found to date is in the snail Biomphalaria glabrata with a length of only $13.6 \mathrm{~kb}$ (DeJong et al. 2004) and the largest known was found in Scapharca subcrenata at $48.2 \mathrm{~kb}$ (Hou et al. 2016). The mitogenome for the sea scallop Placopecten magellanicus is $30.7 \mathrm{~kb}$ when one copy of a $1.4 \mathrm{~kb}$ repeat is present (Smith \& Snyder 2007), but individuals may have anything from two to eight copies of this repeat region (Fuller \& Zouros 1993; La Roche et al. 1990). Smaller repeat regions may also have multiple copy numbers (Fuller \& Zouros 1993). This suggests that the true size of the genome for this species ranges from about $32 \mathrm{~kb}$ in some individuals to almost $41 \mathrm{~kb}$ in others (Smith \& Snyder 2007). 
could further decrease genome size. It is interesting to note that we did not have trouble identifying secondary structures for the tRNA coding for serine in the larger genomes.

\subsubsection{Pseudogenes}

Mitochondrial pseudogenes can be insidious and ubiquitous in some marine invertebrates (Williams \& Knowlton 2001), but are rarely a problem with molluscs. However, close assessment of the assembly of transcriptomic data for L. elliptica showed that a number of reads did not match the consensus sequence. Translation of these sequences into amino acids showed no stop codons using the standard (nuclear) genetic code, but did show stop codons with the appropriate invertebrate mitochondrial code. Given the large number of these reads, we interpret these sequences as pseudogenes rather than sequencing errors. The lack of stop codons in the nuclear code (and the presence of stop codons using the mitochondrial code) suggests that these are nuclear copies that are being transcribed in low numbers. Transcribed copies of pseudogenes have been found in other molluscs (e.g. Korneev et al. 2013) and other organisms, including humans, where they may play a role in regulating genes transcriptionally and post-transcriptionally (Milligan et al. 2016).

\subsubsection{Enrichment}

Enrichment of mitochondrial DNA allows shotgun sequencing of non-model organisms and multiplexing of samples to decrease running costs, however mitochondrial enrichment of divergent lineages is often unsuccessful. Here we show by minor modification to an existing protocol that we can use mitochondrial sequence from one species (Laternula elliptica) as bait to enrich for mitochondria for highly divergent congeneric taxa (L. rostrata).

Although Laternula elliptica and L. rostrata are congeneric, they are considerably divergent. Genetic identity of nucleotides shared between the two sequences for protein-coding genes is $67 \%$ (based on pairwise Muscle alignments for each gene). The two sequences differ by more than $25 \%$ over the barcoding region of COX1 and yet our slight modifications to the mitochondrial enrichment process resulted in a significant increase in coverage for L. rostrata in this study. Attempts to enrich the Bryopa lata sequence using this method failed suggesting that it is too divergent from the bait species. Although this method was only successful within a single genus, the differences we observe in this bivalve genus are equivalent to deeper taxonomic divergences in many other taxa suggesting our modifications to the enrichment process might be useful in other studies. 
Our sequence for the L. elliptica mitogenome differs from a published genomic sequence by only one base pair across the whole genome and from transcriptomic data for protein-coding genes by only $9 \mathrm{bp}$. The 'universal' barcoding region of COX1 differs at most by only $1 \mathrm{bp}$. The similarity of these sequences obtained by different methods acts as confirmation of sequence scoring accuracy but also suggests that the mitogenome may not be useful for population genetic studies in L. elliptica although further sampling is warranted to test this hypothesis. It may also suggest that a single individual's mitogenome is representative of the entire species. Low mitogenomic variability within species is also consistent with nuclear markers; no genetic differences were detected using 68 polymorphic AFLP markers to examine 96 specimens of L. elliptica from two sites in Antarctica, despite population level differences in shell morphology and repair rates (Harper et al. 2012). The morphological differences were interpreted as being ecophenotypic in nature, suggesting a plastic response to environmental differences (Harper et al. 2012). high. As discussed above, even species from the same genus show divergences in excess of $25 \%$.

\section{Conclusion}

The mitogenome is an attractive marker for phylogenetic studies, but our bivalve tree is still not recovering all clades that are expected based on nuclear genes or morphology alone. The inclusion of seven anomalodesmatan and one semelid species into a mitogenome phylogeny for the Autobranchia has resulted in a tree with many robust clades although further improvement is desirable. Relationships among superfamilies or major clades (Pteriomorphia, Palaeoheterodonta, Anomalodesmata, Imparidentia) were not well supported but some major taxon groups are still missing. Compositional bias in the mitogenome may account in part for some anomalous phylogenetic relationships. Improved, more even sampling across the bivalve clade with the inclusion of under represented groups like Archiheterodonta, Neotrigonidae and basal euheterodonts is likely to improve the resolution of mitogenome trees. Increased taxon sampling will become easier as sequencing costs decrease and whole genome sequencing makes sequencing mitogenomes easier, making the need to determine the phylogenetic utility of this marker imperative. seen, or only rarely, in other taxa. For example, protein-coding gene boundaries are not as well defined as in gastropods or freshwater bivalves, gene order is extremely variable among species and 
627 transcriptomic and genomic data together enabled better definition of gene boundaries, the

628 identification of possible pseudogenes and suggests that most genes are translated monocistronically.

Acknowledgements

We thank Lisa Smith for help in the lab, Melody Clark for providing transcriptomic data for

632 Laternula elliptica, Mark Youngblood \& Susan Masta for providing the tRNA drawing script, Gonzalo

633 Giribet for providing the photo of Myadora brevis in the graphical abstract and Prashant Sharma and

634 one anonymous reviewer for helpful comments. We gratefully acknowledge the following workshop

635 organisers and Philippe Bouchet (MNHN) for specimens used in this study. Myadora was collected

636 during the International Marine Biological Workshop 2005 organised by Peter Davie. Samples from

637 Singapore were collected as part of the Southern Singapore Marine Biodiversity Survey 2013

638 organized by Tan Koh Siang and colleagues and bivalves from Tjärnö were collected as part of a

639 Swedish Biodiversity Centre workshop organized by Per Sundberg and Malin Strand in 2010. MNHN

640 material was collected during AURORA and PANGLAO 2004 expeditions of the 'Tropical Deep-Sea

641 Benthos' programme under PIs Philippe Bouchet, Danilo Largo (University of San Carlos) and

642 Marivene Manuel (National Museum of the Philippines). PANGLAO 2004 was funded by grants from

643 the Total Foundation, the French Ministry of Foreign Affairs, and the Asean Regional Center for

644 Biodiversity Conservation, and operated under a permit from the Philippine Bureau of Fisheries and

645 Aquatic Resources. AURORA 2007 was funded by the Lounsbery Foundation, and was carried under a

646 Census of Marine Life / Census of Margins umbrella. The authors gratefully acknowledge funding

647 from the Department of Life Sciences at the Natural History Museum. 
Allcock AL, Cooke IR, Strugnell JM (2011) What can the mitochondrial genome reveal about higherlevel phylogeny of the molluscan class Cephalopoda? Zoological Journal of the Linnean Society 161, 573-586.

Altschul SF, Gish W, Miller W, Myers EW, Lipman DJ (1990) Basic local alignment search tool. Journal of Molecular Biology 215, 403-410.

Ballard JWO, Whitlock MC (2004) The incomplete natural history of mitochondria. Mol Ecol 13, 729744.

Bernt M, Donath A, Juhling F, et al. (2013) MITOS: improved de novo metazoan mitochondrial genome annotation. Mol Phylogenet Evol 69, 313-319.

659

660

661

662

Bieler R, Mikkelsen PM, Collins TM, et al. (2014) Investigating the Bivalve Tree of Life - an exemplarbased approach combining molecular and novel morphological characters. Invertebrate Systematics 28, 32.

Bleidorn C, Podsiadlowski L, Zhong M, et al. (2009) On the phylogenetic position of Myzostomida: can 77 genes get it wrong? BMC Evol Biol 9, 150.

Boore JL (2006) The complete sequence of the mitochondrial genome of Nautilus macromphalus (Mollusca: Cephalopoda). BMC Genomics 7, 182.

Boore JL, Medina M, Rosenberg LA (2004) Complete sequences of the highly rearranged molluscan mitochondrial genomes of the scaphopod Graptacme eborea and the bivalve Mytilus edulis. Mol Biol Evol 21, 1492-1503.

Breton S, Ghiselli F, Passamonti M, et al. (2011a) Evidence for a fourteenth mtDNA-encoded protein in the female-transmitted mtDNA of marine mussels (Bivalvia: Mytilidae). PLoS One 6, e19365.

Breton S, Milani L, Ghiselli F, et al. (2014) A resourceful genome: updating the functional repertoire and evolutionary role of animal mitochondrial DNAs. Trends Genet 30, 555-564.

Breton S, Stewart DT, Shepardson S, et al. (2011b) Novel protein genes in animal mtDNA: a new sex determination system in freshwater mussels (Bivalvia: Unionoida)? Mol Biol Evol 28, 16451659 .

Carapelli A, Comandi S, Convey P, Nardi F, Frati F (2008) The complete mitochondrial genome of the Antarctic springtail Cryptopygus antarcticus (Hexapoda: Collembola). BMC Genomics 9, 315.

Casastrena J (2000) Selection of conserved blocks from multiple alignments for their use in phylogenetic analysis. Mol Biol Evol 17, 540-552.

Checa AG, Pina CM, Osuna-Mascaró AJ, Rodríguez-Navarro AB, Harper EM (2014) Crystalline organization of the fibrous prismatic calcitic layer of the Mediterranean mussel Mytilus galloprovincialis. European Journal of Mineralogy 26, 495-505.

Checa AG, Rodriguez-Navarro AB, Esteban-Delgado FJ (2005) The nature and formation of calcitic columnar prismatic shell layers in pteriomorphian bivalves. Biomaterials 26, 6404-6414. 
Clark MS, Thorne MA, Vieira FA, et al. (2010) Insights into shell deposition in the Antarctic bivalve Laternula elliptica: gene discovery in the mantle transcriptome using 454 pyrosequencing. BMC Genomics 11, 362.

Combosch DJ, Collins TM, Glover EA, et al. (2016) A family-level tree of life for bivalves based on a Sanger-sequencing approach. Mol Phylogenet Evol 107, 191-208.

Combosch DJ, Giribet G (2016) Clarifying phylogenetic relationships and the evolutionary history of the bivalve order Arcida (Mollusca: Bivalvia: Pteriomorphia). Mol Phylogenet Evol 94, 298312.

Cunha RL, Grande C, Zardoya R (2009) Neogastropod phylogenetic relationships based on entire mitochondrial genomes. BMC Evol Biol 9, 210.

Dabney J, Knapp M, Glocke I, et al. (2013) Complete mitochondrial genome sequence of a Middle Pleistocene cave bear reconstructed from ultrashort DNA fragments. Proc Natl Acad Sci U SA 110, 15758-15763.

Darling ACE, Mau B, Blattner FR, Perna NT (2004) Mauve: multiple alignment of conserved genomic sequence with rearrangements. Genome Research 14, 1394-1403.

DeJong RJ, Emery AM, Adema CM (2004) The mitochondrial genome of Biomphalaria glabrata (Gastropoda: Basommatophora), intermediate host of Schistosoma mansoni. Journal of Parasitology 90, 991-997.

Foster PG (2004) Modeling compositional heterogeneity. Systematic Biology 53, 485-495.

Fuller KM, Zouros E (1993) Dipsersed discrete length polymorphism of mitochondrial DNA in the scallop Placopecten magellanicus. Current Genetics 23, 365-369.

Gascuel O (1997) BIONJ: an improved version of the NJ algorithm based on a simple model of sequence data. Mol Biol Evol 14, 685-695.

Giribet G, Distel DL (2003) Bivalve phylogeny and molecular data. In: Molecular Systematics and Phylogeography of Mollusks (eds. Lydeard C, Lindberg DR), pp. 45-90. Smithsonian Books, Washington, D.C.

Giribet G, Wheeler W (2002) On Bivalve Phylogeny- A High-Level Analysis of the Bivalvia (Mollusca) Based on Combined Morphology and DNA Sequence Data. Invertebrate Biology 121, 271324.

Gonzalez VL, Andrade SC, Bieler R, et al. (2015) A phylogenetic backbone for Bivalvia: an RNA-seq approach. Proceedings of the Royal Society B 282, 20142332.

Harper EM, Clark MS, Hoffman Jl, et al. (2012) Iceberg scour and shell damage in the Antarctic bivalve Laternula elliptica. PLoS One 7, e46341.

Harper EM, Dreyer H, Steiner G (2006) Reconstructing the Anomalodesmata (Mollusca: Bivalvia): morphology and molecules. Zoological Journal of the Linnean Society.

Hou Y, Wu B, Liu Z-H, et al. (2016) Complete mitochondrial genome of ark shell Scapharca subcrenata. Mitochondrial DNA Part A 27, 939-940. 
Kim S, Lim BJ, Min GS, Choi HG (2013) The complete mitochondrial genome of Arctic Calanus hyperboreus (Copepoda, Calanoida) reveals characteristic patterns in calanoid mitochondrial genome. Gene 520, 64-72.

Knudsen J (1970) The systematics and biology of abyssal and hadal Bivalvia. Galathea 11.

Kocot KM, Cannon JT, Todt C, et al. (2011) Phylogenomics reveals deep molluscan relationships. Nature 477, 452-456.

Korneev SA, Kemenes I, Bettini NL, et al. (2013) Axonal trafficking of an antisense RNA transcribed from a pseudogene is regulated by classical conditioning. Sci Rep 3, 1027.

Krause J, Fu Q, Good JM, et al. (2010) The complete mitochondrial DNA genome of an unknown hominin from southern Siberia. Nature 464, 894-897.

La Roche J, Snyder M, Cook DI, Fuller K, Zouros E (1990) Molecular characterization of a repeat element causing large-scale size variation in the mitochondrial DNA of the sea scallop Placopecten magellanicus. Mol Biol Evol 7, 45-64.

Lartillot N, Lepage T, Blanquart S (2009) PhyloBayes 3: a Bayesian software package for phylogenetic reconstruction and molecular dating. Bioinformatics 25, 2286-2288.

Laslett D, Canbäck B (2008) ARWEN: a program to detect tRNA genes in metazoan mitochondrial nucleotide sequences. Bioinformatics 24, 172-175.

Lee $\mathrm{H}$, Samadi S, Puillandre N, et al. (2016) Eight new mitogenomes for exploring the phylogeny and classification of Vetigastropoda. Journal of Molluscan Studies 82, 534-541.

Lemer S, Gonzalez VL, Bieler R, Giribet G (2016) Cementing mussels to oysters in the pteriomorphian tree: a phylogenomic approach. Proceedings of the Royal Society $B 283$.

Lockhart PJ, Steel MA, Hendy MD, Penny D (1994) Recovering evolutionary trees under a more realistic model of sequence evolution. Mol Biol Evol 11, 605-612.

Maricic T, Whitten M, Paabo S (2010) Multiplexed DNA sequence capture of mitochondrial genomes using PCR products. PLoS One 5, e14004.

Milligan MJ, Harvey E, Yu A, et al. (2016) Global Intersection of Long Non-Coding RNAs with Processed and Unprocessed Pseudogenes in the Human Genome. Front Genet 7, 26.

Mizi A, Zouros E, Moschonas N, Rodakis GC (2005) The complete maternal and paternal mitochondrial genomes of the Mediterranean mussel Mytilus galloprovincialis: implications for the doubly uniparental inheritance mode of mtDNA. Mol Biol Evol 22, 952-967.

Morton B (1985) Adaptive radiation in the Anomalodesmata. In: The Mollusca, Vol. 10. Evolution. (eds. Trueman ER, Clarke MR), pp. 405-459. Academic Press, Orlando.

Okimoto R, Wolstenholme DR (1990) A set of tRNAs that lack either the TYC arm or the dihydrouridine arm: towards a minimal tRNA adaptor. EMBO Journal 9, 3405-3411.

Osca D, Templado J, Zardoya R (2015) Caenogastropod mitogenomics. Mol Phylogenet Evol 93, 118128. 
Park H, Ahn dH (2015) Complete mitochondrial genome of the Antarctic soft-shelled clam, Laternula elliptica (Bivalvia; Laternulidae). Mitochondrial DNA 26, 642-643.

Plazzi F, Ceregato A, Taviani M, Passamonti M (2011) A molecular phylogeny of bivalve mollusks: ancient radiations and divergences as revealed by mitochondrial genes. PLoS One 6, e27147.

Plazzi F, Ferrucci RR, Passamonti M (2010) Phylogenetic representativeness: a new method for evaluating taxon sampling in evolutionary studies. BMC Bioinformatics 11, 209-223.

Plazzi F, Passamonti M (2010) Towards a molecular phylogeny of Mollusks: bivalves' early evolution as revealed by mitochondrial genes. Mol Phylogenet Evol 57, 641-657.

Plazzi F, Ribani A, Passamonti M (2013) The complete mitochondrial genome of Solemya velum (Mollusca: Bivalvia) and its relationships with Conchifera. BMC Genomics 14, 409.

Rota-Stabelli O, Lartillot N, Philippe H, Pisani D (2013) Serine codon-usage bias in deep phylogenomics: pancrustacean relationships as a case study. Syst Biol 62, 121-133.

Serb JM, Lydeard C (2003) Complete mtDNA sequence of the North American freshwater mussel, Lampsilis ornata (Unionidae): an examination of the evolution and phylogenetic utility of mitochondrial genome organization in Bivalvia (Mollusca). Mol Biol Evol 20, 1854-1866.

Sharma PP, Gonzalez VL, Kawauchi GY, et al. (2012) Phylogenetic analysis of four nuclear proteinencoding genes largely corroborates the traditional classification of Bivalvia (Mollusca). Mol Phylogenet Evol 65, 64-74.

Sharma PP, Zardus JD, Boyle EE, et al. (2013) Into the deep: a phylogenetic approach to the bivalve subclass Protobranchia. Mol Phylogenet Evol 69, 188-204.

Shen H, Braband A, Scholtz G (2013) Mitogenomic analysis of decapod crustacean phylogeny corroborates traditional views on their relationships. Mol Phylogenet Evol 66, 776-789.

Sievers F, Wilm A, Dineen D, et al. (2011) Fast, scalable generation of high-quality protein multiple sequence alignments using Clustal Omega. Mol Syst Biol 7, 539.

Smith DR (2016) The past, present and future of mitochondrial genomics: have we sequenced enough mtDNAs? Brief Funct Genomics 15, 47-54.

Smith DR, Snyder M (2007) Complete mitochondrial DNA sequence of the scallop Placopecten magellanicus: evidence of transposition leading to an uncharacteristically large mitochondrial genome. J Mol Evol 65, 380-391.

Smith SA, Wilson NG, Goetz FE, et al. (2011) Resolving the evolutionary relationships of molluscs with phylogenomic tools. Nature 480, 364-367.

Steiner G, Hammer S (2000) Molecular phylogeny of the Bivalvia inferred from 18S rDNA sequences with particular reference to the Pteriomorphia. In: The evolutionary biology of the Bivalvia (eds. Harper EM, Taylor JD, Crame JA), pp. 11-29. The Geological Society of London, London, UK.

Strong EE (2003) Refining molluscan characters: morphology, character coding and a phylogeny of the Caenogastropoda. Zoologcal Journal of the Linnean Society 137, 447-554. 
Taylor JD, Glover EA, Williams ST (2008) Ancient chemosynthetic bivalves: systematics of Solemyidae from eastern and southern Australia (Mollusca: Bivalvia). In: Proceedings of the Thirteenth International Marine Biological Workshop, The Marine Fauna and Flora of Moreton Bay, Queensland (eds. Davie PJF, Phillips JA), pp. 75-104. Memoirs of the Queensland Museum Nature Brisbane.

Taylor JD, Williams ST, Glover EA, Dyal P (2007) A molecular phylogeny of heterodont bivalves (Mollusca: Bivalvia: Heterodonta): new analyses of $18 \mathrm{~S}$ and $28 \mathrm{~S}$ rRNA genes. Zoologica Scripta 36, 587-606.

Uribe JE, Kano Y, Templado J, Zardoya R (2016a) Mitogenomics of Vetigastropoda: insights into the evolution of pallial symmetry. Zoologica Scripta 45, 145-159.

Uribe JE, Williams ST, Templado J, Abalde S, Zardoya R (2016b) Denser mitogenomic sampling improves resolution of the phylogeny of the superfamily Trochoidea (Gastropoda: Vetigastropoda). Journal of Molluscan Studies.

Wägele H, Klussmann-Kolb A, Verbeek E, Schrödl M (2013) Flashback and foreshadowing-a review of the taxon Opisthobranchia. Organisms Diversity \& Evolution 14, 133-149.

Wang H, Zhang S, Li Y, Liu B (2010) Complete mtDNA of Meretrix lusoria (Bivalvia: Veneridae) reveals the presence of an atp8 gene, length variation and heteroplasmy in the control region. Comparative Biochemistry and Physiology Part D: Genomics and Proteomics 5, 256-264.

Weigert A, Bleidorn C (2016) Current status of annelid phylogeny. Organisms Diversity \& Evolution 16, 345-362.

Weigert A, Golombek A, Gerth M, et al. (2016) Evolution of mitochondrial gene order in Annelida. Mol Phylogenet Evol 94, 196-206.

Williams ST, Foster PG, Littlewood DT (2014) The complete mitochondrial genome of a turbinid vetigastropod from MiSeq Illumina sequencing of genomic DNA and steps towards a resolved gastropod phylogeny. Gene 533, 38-47.

Williams ST, Knowlton N (2001) Mitochondrial pseudogenes are pervasive and often insidious in the snapping shrimp genus Alpheus. Mol Biol Evol 18, 1484-1493.

Wort EJG, Fenberg PB, Williams ST (2016) Testing the contribution of individual genes in mitochondrial genomes for assessing phylogenetic relationships in Vetigastropoda. Journal of Molluscan Studies.

Wu X, Li X, Li L, et al. (2012a) New features of Asian Crassostrea oyster mitochondrial genomes: a novel alloacceptor tRNA gene recruitment and two novel ORFs. Gene 507, 112-118.

Wu X, Li X, Li L, Yu Z (2012b) A unique tRNA gene family and a novel, highly expressed ORF in the mitochondrial genome of the silver-lip pearl oyster, Pinctada maxima (Bivalvia: Pteriidae). Gene 510, 22-31.

Wyman SK, Jansen RK, Boore JL (2004) Automatic annotation of organellar genomes with DOGMA. Bioinformatics 20, 3252-3255.

Ye J, Coulouris G, Zaretskaya I, et al. (2012) Primer-BLAST: A tool to design target-specific primers for polymerase chain reaction. BMC Bioinformatics 13, 134. 
835

836

837

838
Yuan Y, Li Q, Yu H, Kong L (2012) The complete mitochondrial genomes of six heterodont bivalves (Tellinoidea and Solenoidea): variable gene arrangements and phylogenetic implications. PLoS One 7, e32353. 
840 Graphical abstract. Phylogenetic relationships among 105 autobranch bivalves using amino acid sequences from 11 mitochondrial genes as recovered after Bayesian analysis implemented in PhyloBayes. Photographed specimen is Myadora brevis from Moreton Bay, Queensland Australia. Photo copyright Gonzalo Giribet.

Fig. 1. Phylogenetic relationships among 107 bivalves and 86 gastropods using amino acid sequences from 11 mitochondrial genes as recovered after Bayesian analysis implemented in PhyloBayes. The tree is a consensus of all trees obtained from five runs, with splits not common to all five runs highlighted in red; all differences are in the gastropod clade. Nodal support is provided by posterior probabilities. For the sake of clarity, not all support values are shown. New mitogenomes sequenced in this study are highlighted in red font.

Fig. 2. Phylogenetic relationships among 105 autobranch bivalves (two protobranch species are excluded) using amino acid sequences from 11 mitochondrial genes as recovered after Bayesian analysis implemented in PhyloBayes. The tree is a consensus of all trees obtained from four runs. Nodal support is provided by posterior probabilities. New mitogenomes sequenced in this study are highlighted in red font.

\section{Appendix A. Supplementary material}

Supplementary data 1. Putative secondary structures for mitochondrial tRNAs determined for seven anomalodesmatans and one semelid bivalve. Watson-Crick pairing is shown by lines and G-T pairing by dots. Arrows indicate non-canonical pairings. Secondary structures are not shown for all serine tRNAs.

Supplementary data 2 . Whole genome alignments showing gene rearrangements produced by Mauve (Darling et al. 2004) implemented in Geneious.

Supplementary data 3. Composition tree based on Euclidean distances. Support values are bootstraps. Nodes with less than $10 \%$ support have been collapsed. New mitogenomes sequenced in this study are highlighted in pink font. Two protobranch taxa are highlighted in orange font. 
Table 1. Sample details. Registration number for voucher, family and species identifications for specimens, sampling depth ( $\mathrm{m}$ ) and locality (with longitude and latitude and expedition and station number, where available).

\begin{tabular}{|c|c|c|c|c|}
\hline Reg. No. & Family & Species & Depth (m) & Sampling Locality \\
\hline No voucher & Laternulidae & Laternula elliptica (King, 1832) & - & $\begin{array}{l}\text { Rothera Point, Adelaide Island } \\
\text { Ryder Bay, Antarctica } 67^{\circ} 34^{\prime} \mathrm{S}, 68^{\circ} 8^{\prime} \mathrm{W}\end{array}$ \\
\hline NHMUK 20160581 & Laternulidae & Laternula rostrata (G. B. Sowerby II, 1839) & $0-5$ & $\begin{array}{l}\text { Sungei Buroh, Strait of Johor, Singapore; } 1^{\circ} 26^{\prime} 39.3^{\prime \prime} \mathrm{N} \text {, } \\
103^{\circ} 43^{\prime} 39.39^{\prime \prime} \mathrm{E}\end{array}$ \\
\hline NHMUK 20160582 & Clavagellidae & Bryopa lata (Broderip 1834) & $4-8$ & Singapore; $1^{\circ} 13.9 \mathrm{~N}, 103^{\circ} 52^{\prime} \mathrm{E}$ \\
\hline NHMUK 20160583 & Cuspidariidae & Tropidomya abbreviata (Forbes, 1843) & 70 & Tjarno; $58^{\circ} 56.608 \mathrm{~N}, 11^{\circ} 05.314^{\prime} \mathrm{E}$ \\
\hline NHMUK 20160584 & Lyonsiidae & Lyonsia norwegica (Gmelin, 1791) & 11 & Tjarno; $58^{\circ} 52.424 \mathrm{~N}, 11^{\circ} 06.178^{\prime} \mathrm{N}$ \\
\hline NHMUK 20070216 & Myochamidae & Myodora brevis (G. B. Sowerby I, 1827) & 31 & $\begin{array}{l}\text { N Moreton I., Moreton Bay, Qld, Australia; } 26^{\circ} 56.60^{\prime} \mathrm{S} \text {, } \\
153^{\circ} 24.25^{\prime} \mathrm{E}\end{array}$ \\
\hline MNHN IM-2009-10750 & Euciroidae & Euciroa cf queenslandica Lamprell \& Healy, 1997 & $422-431$ & Philippines; $15^{\circ} 58^{\prime} \mathrm{N}, 121^{\circ} 49^{\prime} \mathrm{E}$; MNHN AURORA 2007, CP2658 \\
\hline MNHN IM-2009-10741 & Semelidae & "Abra" sp & 10 & $\begin{array}{l}\text { Bohol I., Manga, Philippines; } 9^{\circ} 41.8^{\prime} \mathrm{N}, 123^{\circ} 51^{\prime} \mathrm{E} ; \mathrm{MNHN} \text { Panglao } \\
2004, \mathrm{~S} 20\end{array}$ \\
\hline
\end{tabular}


Table 2. Number of amino acid residues (aa) in alignment before and after removal of nonconserved positions with Gblocks. Note that ATP8 was not included in this analysis as it was excluded from phylogenetic analyses given many bivalve taxa were missing this gene. ND4L (in grey font) was also excluded from phylogenetic analyses given that so few sites remained after Gblocks.

\begin{tabular}{|c|c|c|c|}
\hline Dataset - (n) /Gene & $\begin{array}{c}\text { Original } \\
\text { length (aa) }\end{array}$ & $\begin{array}{l}\text { Length } \\
\text { after } \\
\text { Gblocks } \\
\text { (aa) }\end{array}$ & $\begin{array}{c}\% \text { aa } \\
\text { remaining }\end{array}$ \\
\hline \multicolumn{4}{|c|}{ Bivalves+gastropods - 193 taxa } \\
\hline ND1 & 385 & 180 & 46.8 \\
\hline ND2 & 594 & 72 & 12.1 \\
\hline ND3 & 180 & 44 & 24.4 \\
\hline ND4 & 589 & 218 & 37.0 \\
\hline ND4L & 242 & 0 & 0 \\
\hline ND5 & 775 & 217 & 28.0 \\
\hline ND6 & 282 & 14 & 5.0 \\
\hline COX1 & 660 & 484 & 73.3 \\
\hline COX2 & 895 & 147 & 16.4 \\
\hline COX3 & 487 & 177 & 36.3 \\
\hline ATP6 & 499 & 79 & 15.8 \\
\hline CYTB & 540 & 299 & 55.4 \\
\hline all & 5886 & 1931 & 32.8 \\
\hline \multicolumn{4}{|c|}{ Autobranchia only - 105 taxa } \\
\hline ND1 & 366 & 182 & 49.7 \\
\hline ND2 & 493 & 64 & 13.0 \\
\hline ND3 & 183 & 49 & 26.8 \\
\hline ND4 & 536 & 260 & 48.6 \\
\hline ND4L & 200 & 17 & 8.5 \\
\hline ND5 & 752 & 232 & 30.9 \\
\hline ND6 & 285 & 32 & 11.2 \\
\hline COX1 & 653 & 474 & 72.6 \\
\hline COX2 & 895 & 81 & 90.6 \\
\hline cox3 & 436 & 166 & 38.1 \\
\hline ATP6 & 500 & 63 & 12.6 \\
\hline CYTB & 544 & 315 & 58.0 \\
\hline all & 5843 & 1935 & 33.1 \\
\hline
\end{tabular}




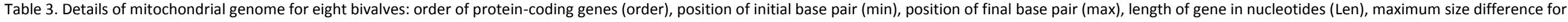
purple shading and bold font. New GenBank accession numbers are given under species names.

\begin{tabular}{|c|c|c|c|c|c|c|c|c|c|c|c|c|c|c|c|c|c|c|c|c|c|c|c|c|c|c|c|c|c|c|c|c|c|}
\hline \multirow{2}{*}{$\begin{array}{l}\text { Species } \\
\text { GenBank Acc \# } \\
\text { Gene }\end{array}$} & \multicolumn{4}{|c|}{$\begin{array}{l}\text { Bryopa lata } \\
\text { KX815957 }\end{array}$} & \multicolumn{4}{|c|}{$\begin{array}{l}\text { Euciroa cf. queenslandica } \\
\qquad \times 1815958\end{array}$} & \multicolumn{4}{|c|}{$\begin{array}{l}\text { Laternula elliptica } \\
\qquad \times 1515959\end{array}$} & \multicolumn{4}{|c|}{$\begin{array}{l}\text { Laternula rostrata } \\
\qquad \times \times 815963\end{array}$} & \multicolumn{4}{|c|}{$\begin{array}{l}\text { Lyonsia norwegica } \\
\text { KX815960 }\end{array}$} & \multicolumn{4}{|c|}{$\begin{array}{c}\text { Myadora brevis } \\
\text { KX815961 }\end{array}$} & \multicolumn{4}{|c|}{$\begin{array}{l}\text { Tropidomya abbreviata } \\
\qquad \mathrm{KX815962}\end{array}$} & \multicolumn{4}{|c|}{$\begin{array}{l}\text { “Abra" sp. } \\
\text { KX815956 }\end{array}$} & \multirow{2}{*}{\begin{tabular}{|c} 
Size \\
Range \\
(bp/aa)
\end{tabular}} \\
\hline & Order & Min & $\operatorname{Max}$ & Len & Order & $\operatorname{Min}$ & $\operatorname{Max}$ & Len & Order & Min & Max & Len & Order & Min & Max & Len & Order & Min & $\operatorname{Max}$ & Len & Order & $\operatorname{Min}$ & $\operatorname{Max}$ & Len & Order & Min & $\operatorname{Max}$ & Len & Order & Min & $\operatorname{Max}$ & Len & \\
\hline TP6 & 7 & 9,830 & 10,615 & 786 & 8 & 8,802 & 9,533 & 732 & 7 & 8,265 & 8,960 & 696 & 7 & 9,734 & 10,429 & 696 & 6 & 4,823 & 5,540 & 718 & 9 & 11,532 & 12,311 & 780 & 10 & 11,378 & 12,052 & 675 & 11 & 13,230 & 13,943 & 714 & $111 / 37$ \\
\hline TTP8 & 10 & 13,547 & 13,708 & 162 & 9 & 9,755 & 9,913 & 159 & 10 & 11,813 & 11,917 & 105 & 10 & 13,312 & 13,416 & 105 & 8 & 7,394 & 7,504 & 111 & 5 & 6,730 & 6,933 & 204 & 3 & 2,064 & 2,291 & 228 & 9 & 11,157 & 11,294 & 138 & $123 / 41$ \\
\hline $0 \times 1$ & 1 & 1 & 1,597 & 1,597 & 1 & 1 & 1,545 & 1,545 & 1 & 1 & 1,581 & 1,581 & 1 & 1 & 1,569 & 1,569 & 1 & 1 & 1,569 & 1,569 & 1 & 1 & 1,596 & 1,596 & 1 & 1 & 1,605 & 1,605 & 1 & 1 & 1,689 & 1,689 & $144 / 48$ \\
\hline $00 \times 2$ & 12 & 14,655 & 15,383 & 729 & 5 & 5,273 & 5,980 & 708 & 12 & 12,713 & 13,408 & 696 & 12 & 14,346 & 15,030 & 685 & 10 & 8,296 & 8,988 & 693 & 2 & 1,665 & 2,372 & 708 & 9 & 10,405 & 11,307 & 903 & 8 & 8,380 & 9,237 & 858 & $144 / 48$ \\
\hline CYTB & 13 & 15,385 & 16,509 & 1,125 & 7 & 7,658 & 8,792 & 1,135 & 13 & 13,420 & 14,551 & 1,132 & 13 & 15,040 & 16,179 & 1,140 & 11 & 9,020 & 10,177 & 1,158 & 11 & 13,446 & 14,591 & 1,146 & 6 & 4,207 & 5,382 & 1,176 & 7 & 7,135 & 8,376 & 1,242 & $117 / 39$ \\
\hline ND1 & 3 & 2,781 & 3,704 & 924 & 10 & 10,056 & 10,988 & 933 & 3 & 4,211 & 5,111 & 901 & 3 & 2,149 & 3,072 & 924 & 12 & 10,245 & 11,157 & 913 & 12 & 14,737 & 15,669 & 933 & 11 & 13,018 & 13,948 & 945 & 5 & 4,335 & 5,258 & 924 & $44 / 14$ \\
\hline ND2 & 8 & 10,632 & 11,669 & 1,038 & 3 & 2,285 & 3,278 & 994 & 8 & 9,029 & 10,051 & 1,023 & 8 & 10,560 & 11,600 & 1,041 & 13 & 11,280 & 12,255 & 976 & 10 & 12,392 & 13,433 & 1,042 & 7 & 5,559 & 6,581 & 1,023 & 13 & 14,857 & 15,918 & 1,062 & $47 / 15$ \\
\hline ND3 & 6 & 9,143 & 9,481 & 339 & 6 & 7,293 & 7,652 & 360 & 6 & 7,858 & 8,196 & 339 & 6 & 9,056 & 9,385 & 330 & 5 & 4,234 & 4,564 & 331 & 8 & 8,371 & 8,727 & 357 & 4 & 3,170 & 3,526 & 357 & 3 & 3,224 & 3,586 & 363 & $33 / 11$ \\
\hline ND4 & 5 & 7,800 & 9,143 & 1,344 & 12 & 12,791 & 14,116 & 1,326 & 5 & 6,106 & 7,458 & 1,353 & 5 & 7,704 & 9,050 & 1,347 & 4 & 2,894 & 4,228 & 1,335 & 13 & 17,705 & 19,072 & 1,368 & 8 & 6,610 & 7,977 & 1,368 & 2 & 1,690 & 3,030 & 1,341 & $42 / 14$ \\
\hline ND4L & 4 & 7,522 & 7,806 & 285 & 11 & 12,513 & 12,791 & 279 & 4 & 5,504 & 5,776 & 273 & 4 & 4,316 & 4,588 & 273 & 3 & 2,619 & 2,900 & 282 & 3 & 2,664 & 2,948 & 285 & 2 & 1,704 & 1,985 & 282 & 4 & 3,721 & 4,011 & 291 & $18 / 6$ \\
\hline ND6 & 2 & 2,173 & 2,673 & 501 & 2 & 1,736 & 2,210 & 475 & 2 & 1,650 & 2,126 & 477 & 2 & 1,688 & 2,149 & 462 & 2 & 2,077 & 2,553 & 477 & 6 & 6,940 & 7,428 & 489 & 5 & 3,654 & 4,148 & 495 & 10 & 11,351 & 11,893 & 543 & $81 / 27$ \\
\hline $12 \mathrm{~S}$ rRNA & - & 19,518 & 20,428 & 911 & - & 6,438 & 7,292 & 855 & - & 3,365 & 4,210 & 846 & - & 6,709 & 7,567 & 859 & - & 12,493 & 13,371 & 879 & - & 10,392 & 11,284 & 893 & - & 12,089 & 12,964 & 876 & - & 9,442 & 10,320 & 879 & 65 \\
\hline 16S rRNA & - & 21,429 & 22,799 & 1,371 & - & 11,344 & 12,481 & 1,138 & - & 2,251 & 3,364 & 1,114 & - & 5,564 & 6,700 & 1,137 & - & 13,407 & 14,586 & 1,180 & - & 8,873 & 10,050 & 1,178 & - & 8,769 & 9,929 & 1,161 & - & 11,978 & 13,151 & 1,174 & 257 \\
\hline Longest NCR & & & & 7,025 & & & & 242 & & & & 78 & & & & 826 & & & & 75 & & & & 1,754 & & & & 601 & & & & 759 & \\
\hline Total genome & & & & $>31,969$ & & & & 15,042 & & & & 14,622 & & & & 16,363 & & & & 14,673 & & & & 19,292 & & & & 16,829 & & & & 16,270 & \\
\hline
\end{tabular}


Table 4. Initiation and termination codons for 13 protein-coding genes in eight bivalve mitochondrial genomes.

\begin{tabular}{|l|c|c|c|c|c|c|c|c|}
\hline $\begin{array}{l}\text { Gene/ } \\
\text { Species }\end{array}$ & $\begin{array}{c}\text { Bryopa } \\
\text { lata }\end{array}$ & $\begin{array}{c}\text { Euciroa cf. } \\
\text { queenslandica }\end{array}$ & $\begin{array}{c}\text { Laternula } \\
\text { elliptica }\end{array}$ & $\begin{array}{c}\text { Laternula } \\
\text { truncata }\end{array}$ & $\begin{array}{c}\text { Lyonsia } \\
\text { norwegica }\end{array}$ & $\begin{array}{c}\text { Myadora } \\
\text { brevis }\end{array}$ & $\begin{array}{c}\text { Tropidomya } \\
\text { abbreviata }\end{array}$ & $\begin{array}{c}\text { "Abra" } \\
\text { sp. }\end{array}$ \\
\hline ATP6 & GTG/TAG & TTG/TAA & GTG/TAA & ATG/TAG & ATG/T & TTG/TAA & ATA/TAG & ATG/TAA \\
\hline ATP8 & ATG/TAA & ATG/TAA & ATC/TAA & ATG/TAA & ATG/TAA & ATG/TAG & GTG/TAA & ATT/TAG \\
\hline COX1 & ATT/T & ATA/TAG & GTG/TAG & ATA/TAA & ATT/TAG & ATA/TAA & ATT/TAG & GTT/TAA \\
\hline COX2 & ATG/TAA & ATG/TAA & ATG/TAG & ATG/T & ATG/TAA & ATG/TAG & GTG/TAA & ATG/TAA \\
\hline COX3 & ATT/TAA & ATG/TAA & ATT/T & ATG/TAG & ATA/T & ATG/TAG & ATG/TAA & GTG/TAA \\
\hline CYTB & GTT/TAA & ATG/T & ATA/T & GTG/TAG & GTG/TAA & GTG/TAG & ATA/TAA & ATA/TAG \\
\hline ND1 & GTG/TAA & ATG/TAA & ATG/T & GTG/TAG & GTG/T & ATG/TAA & GTT/TAA & ATT/TAG \\
\hline ND2 & ATG/TAG & ATG/T & ATG/TAA & ATG/TAG & ATG/T & GTT/T & ATA/TAA & ATG/TAG \\
\hline ND3 & GTG/TAA & ATG/TAA & GTG/TAA & GTT/TAA & GTT/T & GTT/TAA & ATG/TAA & ATG/TAA \\
\hline ND4 & ATT/TAG & ATA/TAA & GTG/TAG & GTG/TAA & GTT/TAG & ATT/TAA & GTT/TAA & ATA/TAG \\
\hline ND4L & ATG/TAG & GTG/TAA & ATG/TAG & ATG/TAG & GTG/TAA & ATG/TAG & ATA/TAA & ATG/TAA \\
\hline ND5 & ATG/TAG & ATG/TAG & ATG/TAA & ATG/TAA & ATG/T & ATG/TAG & ATA/TAA & ATA/TAG \\
\hline ND6 & GTG/TAG & GTG/T & ATG/TAA & ATG/TAG & GTG/TAG & GTG/TAG & ATA/TAG & ATG/TAG \\
\hline
\end{tabular}

Table 5. Frequency with which start/stop codons are used. (Note: truncated T stop codon becomes TAA by the addition of 3' A residues to the $\mathrm{mRNA}$ )

\begin{tabular}{|l|l|}
\hline Start & Stop \\
\hline ATG -46 & TAA -50 \\
\hline GTG -22 & TAG -39 \\
\hline ATA -15 & T -15 \\
\hline GTT -9 & \\
\hline ATT -9 & \\
\hline TTG -2 & \\
\hline ATC -1 & \\
\hline
\end{tabular}


